\title{
Efficient bifacial monolithic perovskite/silicon tandem solar cells via bandgap engineering
}

\author{
Michele De Bastiani ${ }^{1,7}$, Alessandro J. Mirabelli ${ }^{1,6,7}$, Yi Hou ${ }^{2,7}$, Fabrizio Gota ${ }^{3}$, Erkan Aydin ${ }^{1}$, \\ Thomas G. Allen', Joel Troughton', Anand S. Subbiah ${ }^{\circledR 1}$, Furkan H. Isikgor', Jiang Liu', Lujia Xu ${ }^{1}$, \\ Bin Chen², Emmanuel Van Kerschaver', Derya Baran ${ }^{1}{ }^{1}$, Beatrice Fraboni ${ }^{4}$, Michael F. Salvador', \\ Ulrich W. Paetzold ${ }^{3,5}$, Edward H. Sargent $\mathbb{1}^{2 \bowtie}$ and Stefaan De Wolf ${ }^{1 凶}$
}

\begin{abstract}
Bifacial monolithic perovskite/silicon tandem solar cells exploit albedo-the diffuse reflected light from the environment-to increase their performance above that of monofacial perovskite/silicon tandems. Here we report bifacial tandems with certified power conversion efficiencies $>25 \%$ under monofacial AM1.5G 1 sun illumination that reach power-generation densities as high as $\sim 26 \mathrm{~mW} \mathrm{~cm}^{-2}$ under outdoor testing. We investigated the perovskite bandgap required to attain optimized current matching under a variety of realistic illumination and albedo conditions. We then compared the properties of these bifacial tandems exposed to different albedos and provide energy yield calculations for two locations with different environmental conditions. Finally, we present a comparison of outdoor test fields of monofacial and bifacial perovskite/silicon tandems to demonstrate the added value of tandem bifaciality for locations with albedos of practical relevance.
\end{abstract}

lobally, an immense research effort is underway to improve further the power conversion efficiencies (PCEs) of perovskite-based photovoltaics ${ }^{1}$. Recent progress in perovskite-based photovoltaics is founded on the remarkable optoelectronic properties of perovskites, as well as on important advances made in materials and device engineering, such as the formulation of stable compounds and bulk and surface defect passivation strategies $^{2,3}$. Thanks to their high absorption coefficient, tunable bandgap and remarkable defect tolerance, perovskites are also attractive to realize efficient multijunction, tandem devices ${ }^{4}$. The combination of perovskites with market-dominant crystalline silicon (c-Si) solar cells as a bottom cell technology is particularly attractive, as such tandems may increase the PCE of $\mathrm{c}$-Si photovoltaics to values higher than the single-junction thermodynamic limit; ${ }^{4}$ PCE is a key driver of a low levelized cost of electricity at the level of photovoltaics systems ${ }^{5}$.

Perovskite/c-Si tandem research initially focused on stacked, four-terminal tandems owing to the simpler fabrication process $^{6-8}$. However, recent advances in device processing enabled the two-terminal (2T) architecture, with optical advantages that have enabled the highest PCE for perovskite/c-Si tandems ${ }^{9-11}$. For the latest record performance, a front-flat c-Si cell was used; however, from both cost and efficiency perspectives, it is advantageous to use double-side textured $\mathrm{c}$-Si cells ${ }^{12,13}$. Despite this recent progress, further improvements in performance are necessary to push perovskite/c-Si tandems towards market readiness.

Bifaciality offers further increases in the energy yield of $\mathrm{c}-\mathrm{Si}$ photovoltaics, and can be easily implemented using silicon heterojunction (SHJ) technology by replacing the opaque rear metal contact with grid metallization ${ }^{5}$. As the rear side of the cell is transparent, reflected and scattered light from the surroundings (that is, the albedo) contributes to power generation ${ }^{14}$. For optimized single-junction devices, the generated device current increases linearly with the albedo.

Calculations have shown that perovskite/c-Si tandems can also benefit from bifaciality ${ }^{15-18}$. Indeed, recent works explored this for four-terminal tandems, which offer a relatively easily implementable testing platform ${ }^{19}$. However, in the monolithic configuration, bifacial tandems require judicious re-engineering of the perovskite bandgap for this purpose. As shown in previous calculations ${ }^{16,20}$, as top and bottom cells feature larger and smaller bandgaps, respectively, the albedo will only increase the current generated in the bottom cell. In tandems optimized for monofacial use, this may lead to tandem-current mismatch and so a reduction in PCE, which can have a drastic impact on the system-level performance ${ }^{17}$. Therefore, as for conventional current-matching optimizations, the effect of albedo should be accounted for by adjusting the thickness and bandgap of the perovskite top cell ${ }^{15-17,21,22}$.

Monofacial perovskite/c-Si tandems require a perovskite bandgap close to $1.7 \mathrm{eV}$ (ref. ${ }^{23}$ ), which can be achieved by increasing the bromide-to-iodide ratio in the perovskite crystal $^{24}$. However, this may result in phase segregation under prolonged light exposure, which leads to device degradation ${ }^{25}$. Here we show that efficient bifacial tandems, in agreement with recent theoretical predictions, require a narrower perovskite bandgap to achieve current matching, with a close to pure iodide composition, and thereby improve the operational stability of tandems and increase their energy yield.

\section{Perovskite/silicon bifacial tandems}

In the field, solar photons that strike the rear side of the device mainly originate from three sources: direct and diffuse sunlight

'KAUST Solar Center (KSC), Physical Sciences and Engineering Division (PSE), King Abdullah University of Science and Technology (KAUST), Thuwal, Kingdom of Saudi Arabia. ${ }^{2}$ Department of Electrical and Computer Engineering, University of Toronto, Toronto, Ontario, Canada. ${ }^{3}$ Institute of Microstructure Technology, Karlsruhe Institute of Technology, Eggenstein- Leopoldshafen, Germany. ${ }^{4}$ Department of Physics and Astronomy, University of Bologna, Bologna, Italy. ${ }^{5}$ Light Technology Institute Karlsruhe Institute of Technology, Karlsruhe, Germany. ${ }^{6}$ Present address: Department of Physics and Astronomy, Alma Mater Studiorum-University of Bologna, Bologna, Italy. ${ }^{7}$ These authors contributed equally: Michele De Bastiani, Alessandro J. Mirabelli, Yi Hou.凶e-mail: ted.sargent@utoronto.ca; stefaan.dewolf@kaust.edu.sa 
reflected off the ground and surroundings, as well as diffuse sunlight scattered in the atmosphere (Fig. 1a). Direct and diffuse light reflected by the ground is commonly referred to as albedo (non-dimensional); we use the term rear irradiance $\left(\mathrm{mW} \mathrm{cm}^{-2}\right)$ to refer to artificial rear-side illumination in the lab, which we use to study bifaciality. To characterize the performance of tandems, we used PCE (\%) for measurements at standard test conditions (STCs) (that is, under monofacial standard test conditions, AM1.5G spectrum, 1 sun front-side illumination) and power generation density (PGD) $\left(\mathrm{mW} \mathrm{cm}^{-2}\right)$ for measurements under STCs with additional rear irradiance in the lab, as well as test field measurements. When referring to the PGD at a specific rear irradiance, we use the bifaciality factor $(\mathrm{BiFi})$ to indicate the intensity of the rear irradiance (that is, $\mathrm{PGD}_{\mathrm{BiF}_{2} 20} 26$, means $26 \mathrm{~mW} \mathrm{~cm}^{-2}$ with $200 \mathrm{~W} \mathrm{~m}^{-2}$ of rear irradiance).

To understand the impact of albedo on the performance of bifacial perovskite/c-Si tandems, we developed such devices that employed perovskites with different bandgaps. Our tandem layout consisted of a both-sides textured SHJ bottom cell, onto which the perovskite top cell was deposited by solution processing in the $\mathrm{p}-\mathrm{i}-\mathrm{n}$ configuration (which implies the electrons were collected at the sunward side). Figures $1 \mathrm{~b}, \mathrm{c}$ sketch this tandem and show a cross-sectional scanning electron micrograph, respectively. To increase the bifaciality, the $\mathrm{SHJ}$ rear contact was optimized to combine a minimized series resistance and maximal albedo coupling into the c-Si cell (Fig. 1d).

We experimentally fabricated bifacial perovskite/c-Si tandems with five different perovskite bandgaps (1.59, 1.62, 1.65, 1.68 and $1.7 \mathrm{eV}$, determined from photoluminescence spectroscopy; Supplementary Fig. 1) by altering the iodide-to-bromide ratio. Figure 1e and Supplementary Table 1 show the statistical distribution of the photovoltaic parameters for the tandem cells with different perovskite bandgaps, measured under monofacial STC. As expected, the wider the perovskite bandgap, the larger the open circuit voltage $\left(V_{\mathrm{OC}}\right)$ of the tandems. The tandem short-circuit current density $J_{\mathrm{SC} \text { tandem }}$ reaches a maximum at a perovskite bandgap of $1.68 \mathrm{eV}$, which corresponds to the optimal current matching between the subcells of the tandems discussed here, and results in an independently certified PCE of $25.2 \%$ under STCs (Supplementary Fig. 2). Perovskite bandgaps smaller than $1.68 \mathrm{eV}$ result in a lower overall $J_{\text {SC_tandem }_{2}}$, as the c-Si subcell becomes current limiting. Similarly, perovskite bandgaps larger than $1.68 \mathrm{eV}$ also result in a lower overall $J_{\mathrm{SC} \text { tandem }}$, as the perovskite subcell becomes current limiting. The fill factor (FF) is slightly higher under silicon-limited conditions than under perovskite-limited conditions, which is in agreement with other reports ${ }^{26,27}$. Overall, the PCE under STCs remains close to $25 \%$ for tandems with perovskite bandgaps of $1.65,1.68$ and $1.7 \mathrm{eV}$.

To investigate experimentally the role of rear irradiance, we measured the bifacial tandems by placing them between two solar simulators. The front illumination (perovskite side) was kept at 1 sun $\left(100 \mathrm{~mW} \mathrm{~cm}^{-2}\right)$, whereas the rear of the device (silicon side) was illuminated with intensities that ranged from 0 to $\sim 95 \mathrm{~mW} \mathrm{~cm}^{-2}$ (that is, 0.95 sun equivalent); Supplementary Fig. 3 shows the detailed characterization set-up. To facilitate the contact and prevent cell degradation during the experiment, the devices were vacuum laminated between two sheets of glass, using butyl rubber as the edge sealant. Note that we used single-lamp solar simulators for practical convenience; as their spectra vary somewhat from the AM1.5G spectrum, dual-lamp or light-emitting diode (LED)-based simulators would be more ideal for tandem measurements (see Supplementary Fig. 3 for more details $)^{28}$.

Figure if compares the $J-V$ curves of a bifacial tandem (perovskite bandgap of $1.62 \mathrm{eV}$ ) before encapsulation measured with an LED-based solar simulator (brown) and after encapsulation measured with the bifacial set-up without rear irradiation (dark red). For the latter, the reduction in $J_{\mathrm{SC}}\left(1-1.5 \mathrm{~mA} \mathrm{~cm}^{-2}\right)$ is caused both by the glass encapsulation (front-glass reflection and suboptimal refractive-index matching of the glass/vacuum/top-electrode stack that increases the reflection losses), but also by the different frontside solar simulator used in the bifacial set-up (Supplementary Fig. 3). Figure if also shows that the bifacial tandem $(1.62 \mathrm{eV}$ (brown)) generates a slightly lower current $\left(\sim 0.5 \mathrm{mAcm}^{-2}\right)$ in monofacial operation mode, when compared with an opaque metal rear electrode-the latter aids internal light trapping in the $\mathrm{c}-\mathrm{Si}$ cell $(1.68 \mathrm{eV} \text { (blue) })^{29}$. However, in the presence of a $20 \mathrm{~mW} \mathrm{~cm}^{-2}$ rear irradiance (orange), $J_{\mathrm{SC} \text { tandem }}$ clearly surpasses its monofacial counterparts. Here we underline that such an albedo is realistic for industrial solar parks optimized to operate with bifacial modules. In the near future, it is likely that albedos that result in rear irradiances as high as $30 \mathrm{~mW} \mathrm{~cm}^{-2}$ may be achieved, for example, with the implementation of a reflective coating that covers the ground and proper site selection ${ }^{30}$.

To thoroughly explore the bifacial configuration, in Fig. 1g we show the change in device performance as a function of the rear irradiance, which ranges from 0 to $\sim 95 \mathrm{~mW} \mathrm{~cm}^{-2}$, of encapsulated bifacial tandems with different perovskite bandgaps. In general, the tandem $V_{\mathrm{OC}}$ slightly increases with rear irradiance by around $20 \mathrm{mV}$, as expected given the higher density of photogenerated charge carriers in the bottom cell. However, $J_{\text {SC tandem }}$ is the parameter that benefits most from the presence of albedo. As the rear irradiance increases, $J_{\mathrm{SC} \_ \text {tandem }}$ rises rapidly, to plateau at $\sim 20 \mathrm{~mW} \mathrm{~cm}^{-2}$ of rear irradiance for most bandgaps tested. The enhancement in $J_{\text {SC_tandem }_{1}}$ with rear irradiance is most pronounced for the narrower bandgap perovskites tested $(1.59$ and $1.62 \mathrm{eV})$. The reason is that both subcells simultaneously generate more current: the perovskite top cell due its smaller bandgap, and the c-Si bottom cell due to the rear irradiance. Both experimental and calculated data show that, with decreasing bandgaps, the rear irradiance required to achieve current matching slightly increases. The effect of albedo on the FF is more complex. For all band gaps, the FF slightly drops as the rear irradiance increases from 0 to $20 \mathrm{~mW} \mathrm{~cm}^{-2}$ before partially recovering at irradiations higher than $\sim 20 \mathrm{~mW} \mathrm{~cm}^{-2}$. A similar correlation between FF and current-matching conditions is well known for monofacial tandems when the incident solar radiation is spectrally changed ${ }^{26,27}$ (for a detailed explanation of this phenomenon, see Supplementary Note 1). As demonstrated in Fig. 1g and Supplementary Table 1, $J_{\text {SC }}$ strongly increases with stronger rear irradiances up to values of around $10-20 \mathrm{~mW} \mathrm{~cm}^{-2}$, which empirically demonstrates the extent to which the tandems tested under monofacial STCs are current limited by the c-Si bottom cell. Along with improved current matching, the FF slightly decreases, as previously shown for basic two-diode considerations (Supplementary Fig. 6). For a rear irradiance that exceeds $20 \mathrm{~mW} \mathrm{~cm}^{-2}$, the tandems enter the regime of current limitation by the perovskite top cell as no further enhancement in $J_{\mathrm{SC}}$ is observed with increases in the rear irradiance. For this regime, the tandem again shows a slightly increased FF. As stated earlier, in the presence of albedo, we use PGD rather than PCE to indicate the performance of bifacial tandems. Similar to the $J_{\mathrm{SC}}$ trend, the PGD of the bifacial tandem strongly benefits from the addition of rear irradiance, to achieve values as high as $\sim 28 \mathrm{~mW} \mathrm{~cm}^{-2}$ for perovskites with band gaps of 1.59 and $1.62 \mathrm{eV}$ (with $\sim 95 \mathrm{~mW} \mathrm{~cm}^{-2}$ of rear irradiance, that is, $\left.\mathrm{PGD}_{\text {BiFi950 }}=27.85 \mathrm{~mW} \mathrm{~cm}^{-2}\right)$. Notably, our measurements show that a rear irradiance of $30 \mathrm{~mW} \mathrm{~cm}^{-2}$ can improve the absolute PGD of a bifacial tandem (with a $1.59 \mathrm{eV}$ perovskite top cell) by more than $25 \%$ with respect to its monofacial configuration (see Supplementary Fig. 7 for more details). Such an albedo is realistic in solar fields, in which snow, sand or concrete may cover the ground surface ${ }^{22,31}$. When compared with monofacial perovskite/c-Si tandems, this enhancement in power output favours bifacial technology over several monofacial configurations, as shown in Supplementary Table 5, which underlines the potential of this technology. 
a

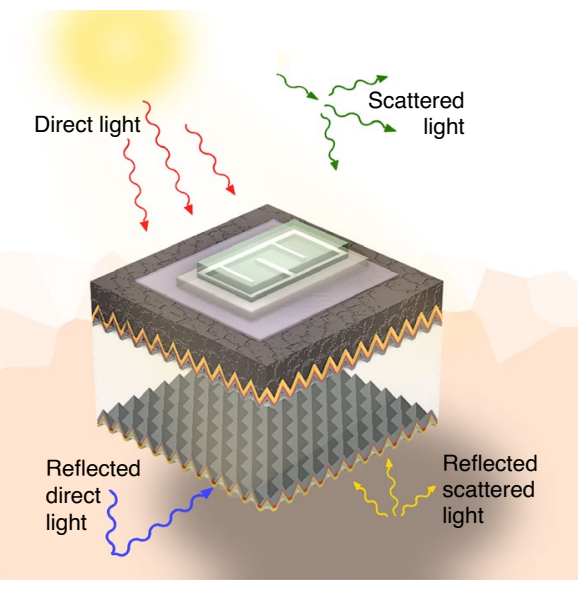

b

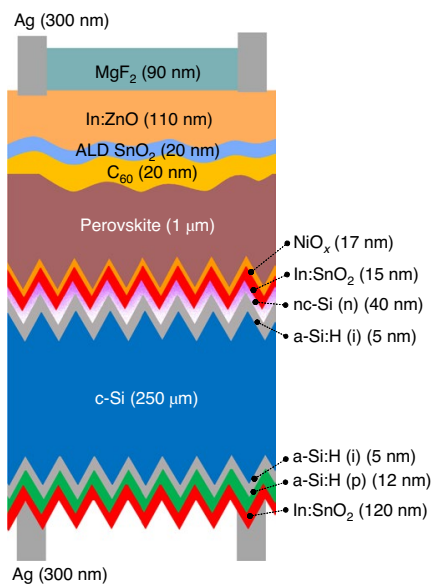

c

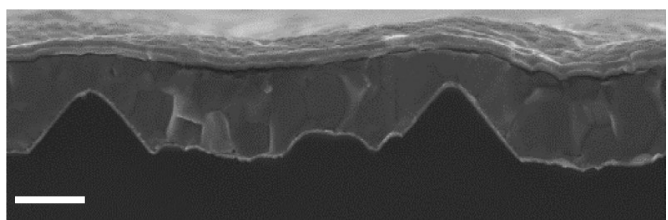

d

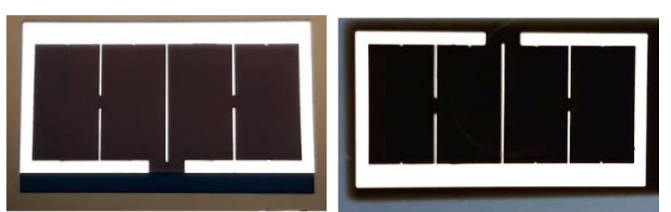

e
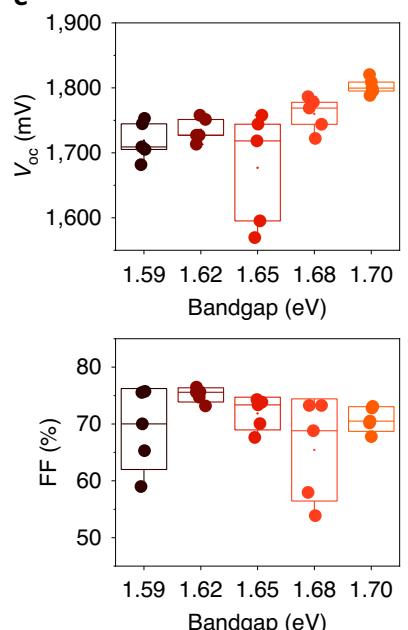

g
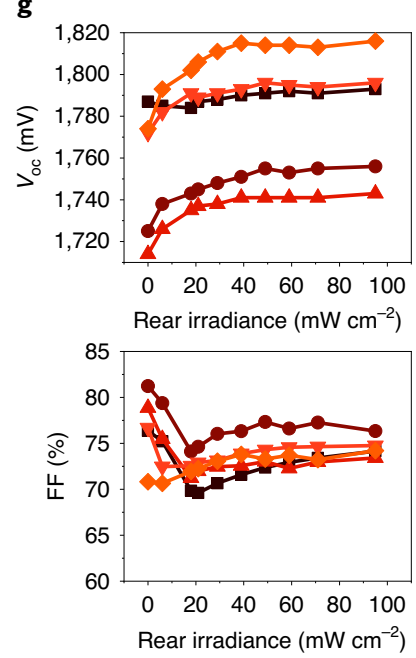
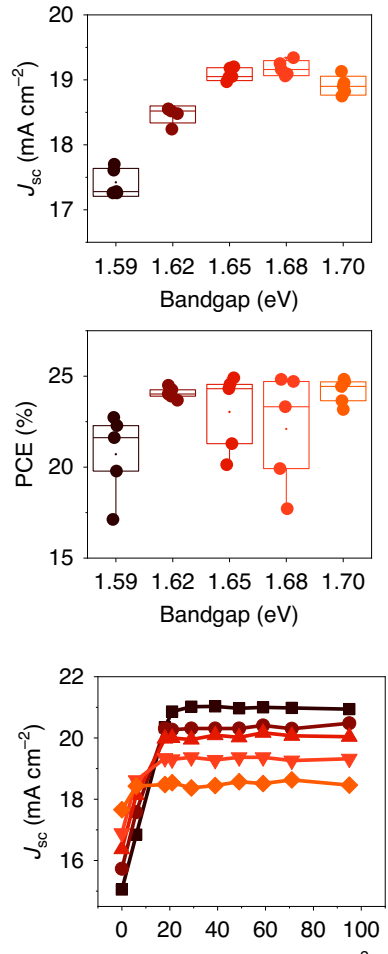

Rear irradiance $\left(\mathrm{mW} \mathrm{cm}^{-2}\right)$

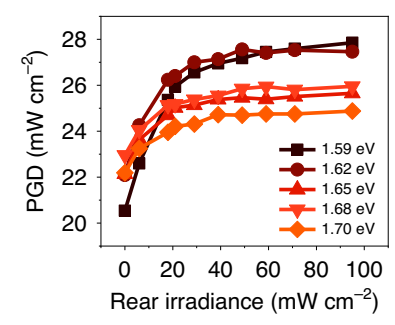

f

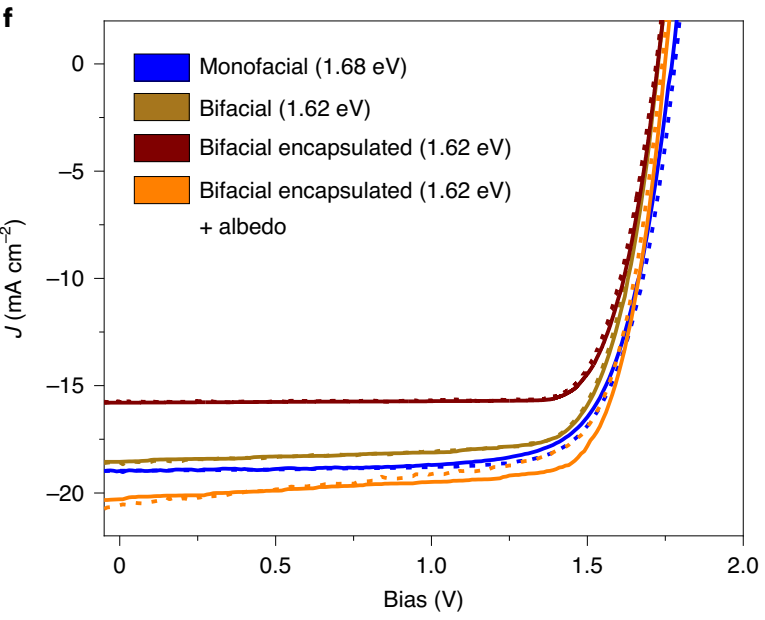

h

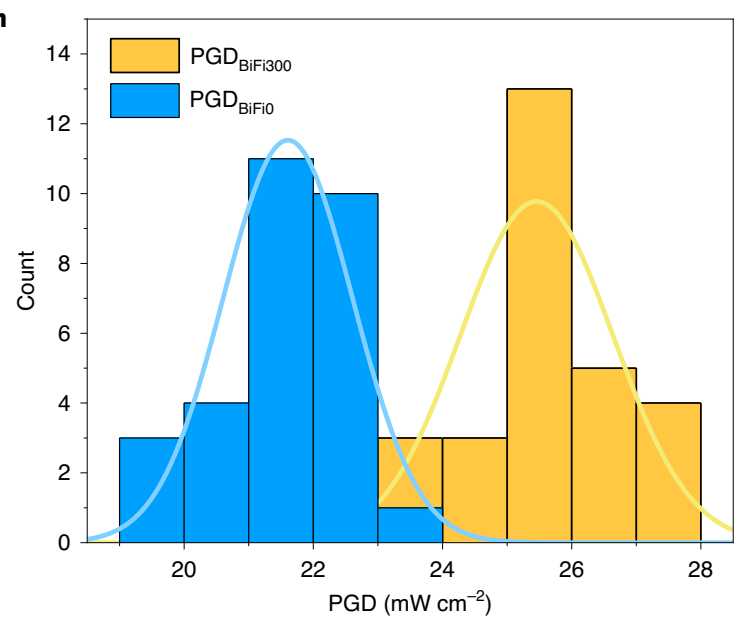

Fig. 1 | Perovskite/silicon bifacial tandems. a, Sketch of light absorption in a bifacial perovskite/c-Si tandem with albedo featured. a-Si, amorphous silicon; $\mathrm{Si}: \mathrm{H}$, hydrogenated silicon; nc-Si, nanocrystalline silicon; a-Si:H, hydrogenated amorphous silicon. b, Cross-sectional sketch of the perovskite/c-Si bifacial tandem. c, Cross-section scanning electron micrograph of the tandem realized on a both-sides textured c-Si bottom cell. Scale bar, $1 \mu$ m. $\mathbf{d}$, Pictures of the front (left) and rear (right) contacts of the device. e, Photovoltaic performance for bifacial tandems with different perovskite bandgaps, measured only with

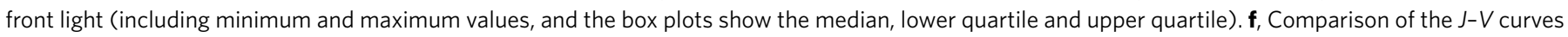
of a monofacial tandem and a bifacial tandem measured using an LED-based solar simulator. The same bifacial device was encapsulated and measured in the bifacial set-up with front light only and front light plus rear irradiance. Solid lines show the reverse voltage scan direction and dashed lines the forward voltage scan direction. $\mathbf{g}$, Photovoltaic performance of bifacial tandems with different perovskite bandgaps as a function of the rear irradiance. $\mathbf{h}$, Statistical distribution of the PGD of 29 tandems measured with and without rear irradiance. The respective fits are included as a guide for the eye. ALD, atomic layer deposition. 

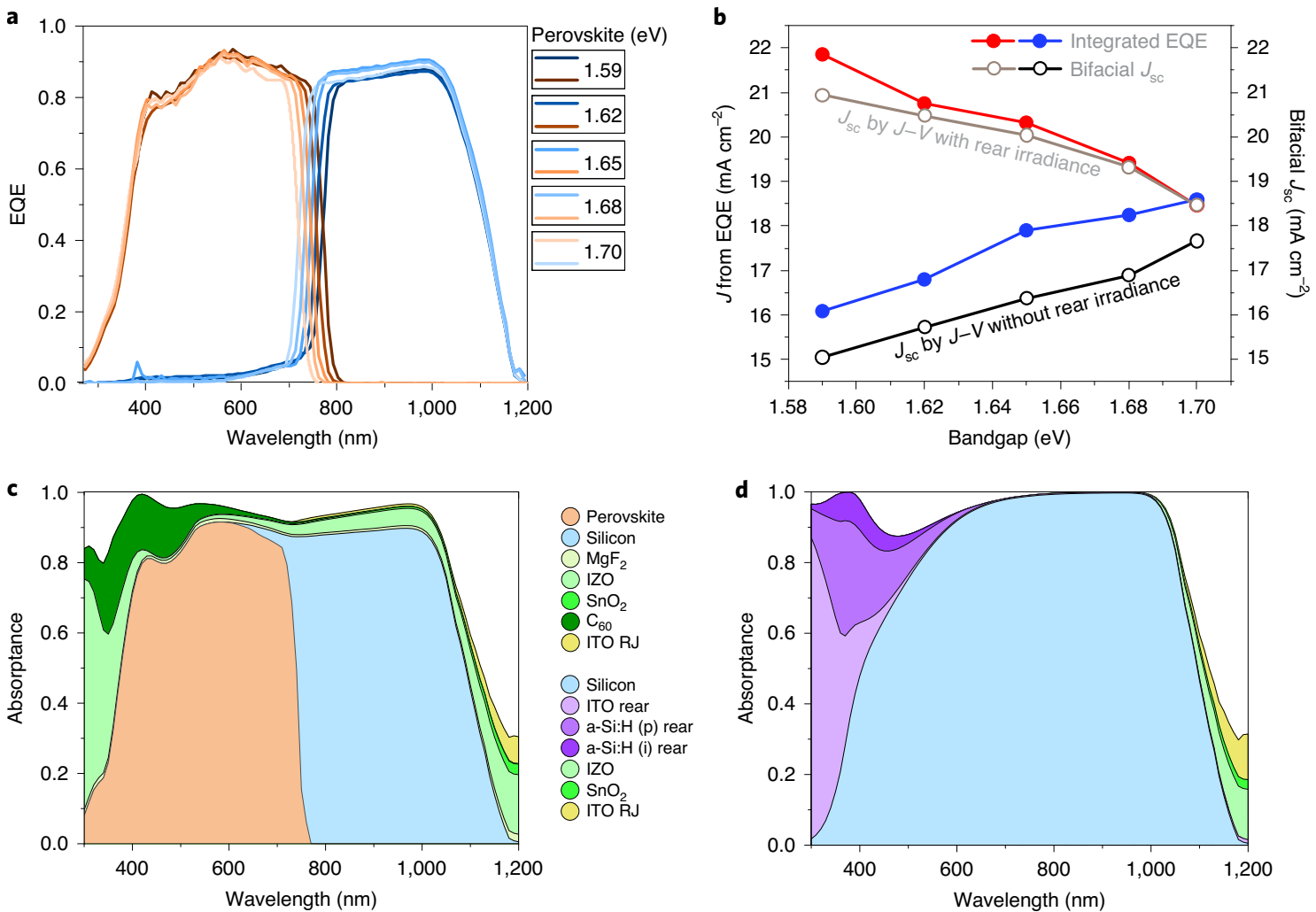

Fig. 2 | Optical analysis. a, EQEs of the bifacial tandems with different bandgaps. The orange lines correspond to the EQE of the perovskite top cell; and the blue lines to the EQE of the silicon bottom cells. b. Comparison between the integrated EQE current density and $J_{S C}$ from $J-V$ curves. Note that the EQE measurements were performed without encapsulation, but the $J-V$ measurements were done with encapsulation, which lowers the $J_{\mathrm{SC}}$ compared with the EQE values. Full dots show the integrated EQE current density for the perovskite (red) and c-Si (blue) as a function of the perovskite bandgap. Hollow circles show $J_{\mathrm{SC}}$ of the bifacial device without rear irradiance (black) and with rear irradiance (grey, $\sim 95 \mathrm{~mW} \mathrm{~cm}^{-2}$ ) as a function of the perovskite bandgap, extrapolated from Fig. 1g. c,d Front (c) and rear (d) side absorption of the layers that compose the bifacial tandem with a perovskite bandgap of $1.68 \mathrm{eV}$. ITO, indium tin oxide. RJ, recombination junction.

To test our findings, we analysed the enhancement in PGD for a batch of 29 bifacial tandem cells (with a perovskite bandgap of $1.59 \mathrm{eV}$ ), with and without $30 \mathrm{~mW} \mathrm{~cm}^{-2}$ of rear irradiance (Fig. $1 \mathrm{~h})$. Without albedo, the devices showed a distribution of $\mathrm{PGD}_{\mathrm{BiF}}$ centred at $21.5 \mathrm{~mW} \mathrm{~cm}^{-2}$. Conversely, with a rear irradiance of $30 \mathrm{~mW} \mathrm{~cm}^{-2}$, the overall $\mathrm{PGD}_{\text {Bii ii30 }}$ increased and the average shifted to $25.5 \mathrm{~mW} \mathrm{~cm}^{-2}$, an absolute increase of $19 \%$ in power generation.

With rear irradiance, the operating temperature of the tandem increases. In Supplementary Fig. 8, we illustrate the temperature variation under different rear irradiance conditions alongside their relative cooling relaxation times. Based on these cooling times, we established a minimum time interval between the sequential measurements carried out in the lab for Fig. 1g, to ensure a cell temperature close to that of the STCs. However, the outdoor operational temperature of a solar cell (especially in a sunny and hot climates) can reach $50^{\circ} \mathrm{C}$ and more (Supplementary Fig. 9), even for perovskite/c-Si tandems in which thermalization losses are notably reduced compared with those of single-junction devices.

\section{Optics and light harvesting}

To further understand the current-matching conditions for bifacial tandems, we collected external quantum efficiency (EQE) spectra for the devices with different perovskite bandgaps (Fig. 2a). By integrating the EQE-weighted solar spectrum, we can extract the current-matching condition (for the monofacial tandem case) achieved for a perovskite bandgap between 1.68 and $1.7 \mathrm{eV}$, in agreement with the trend for $J_{\mathrm{SC}}$ shown in Fig. 1e. To visualize the influence of the bandgap of the perovskite on $J_{\text {SC_tandem }}$, Fig. $2 \mathrm{~b}$ shows plots (closed circles)of the integrated currents derived from the EQEs in Fig. 2a for both the perovskite (red) and silicon (blue) subcells versus the perovskite bandgap; we note that altering the perovskite bandgap does not notably alter its refractive index, and therefore the overall reflection of the tandem is not altered (Supplementary Fig. 10). We further compared these currents with those obtained from $J-V$ measurements (Fig. 1g), shown in Fig. 2 b by hollow circles for bifacial devices with a $\sim 95 \mathrm{~mW} \mathrm{~cm}^{-2}$ rear irradiance (red) and without an effective albedo (blue). Figure $2 \mathrm{~b}$ again demonstrates that, although a $1.7 \mathrm{eV}$ perovskite bandgap is optimal for monofacial tandems, in the bifacial configuration this offers little to no gain in current. For smaller bandgaps (for example. $1.59 \mathrm{eV}$; Fig. 3b), the 1 sun integrated EQE shows a remarkable mismatch in current, due to a current limiting c-Si subcell. However, although this is disadvantageous in a monofacial configuration, it enables the highest current gain in the bifacial configuration, provided that sufficient rear irradiance is available.

To further analyse possible loss mechanisms due to optical effects as a function of the layer stack, we performed optical simulations. Figure $2 c$, d shows the front and rear side absorptance, respectively, given the layers of the stack of Fig. $1 \mathrm{~b}$ for a perovskite bandgap of $1.68 \mathrm{eV}$ (see Supplementary Fig. 11 for details). The indium zinc oxide (IZO) and fullerene $\left(\mathrm{C}_{60}\right)$ top layers cause substantial parasitic absorption in the ultraviolet regime. Moreover, the IZO layer also induces losses due to free carrier absorption between 800 and $1,100 \mathrm{~nm}$, a range in which the c-Si bottom features a high quantum efficiency, and thus remarkably affects the current output. Overall, under AM1.5G 1 sun illumination, parasitic absorption 

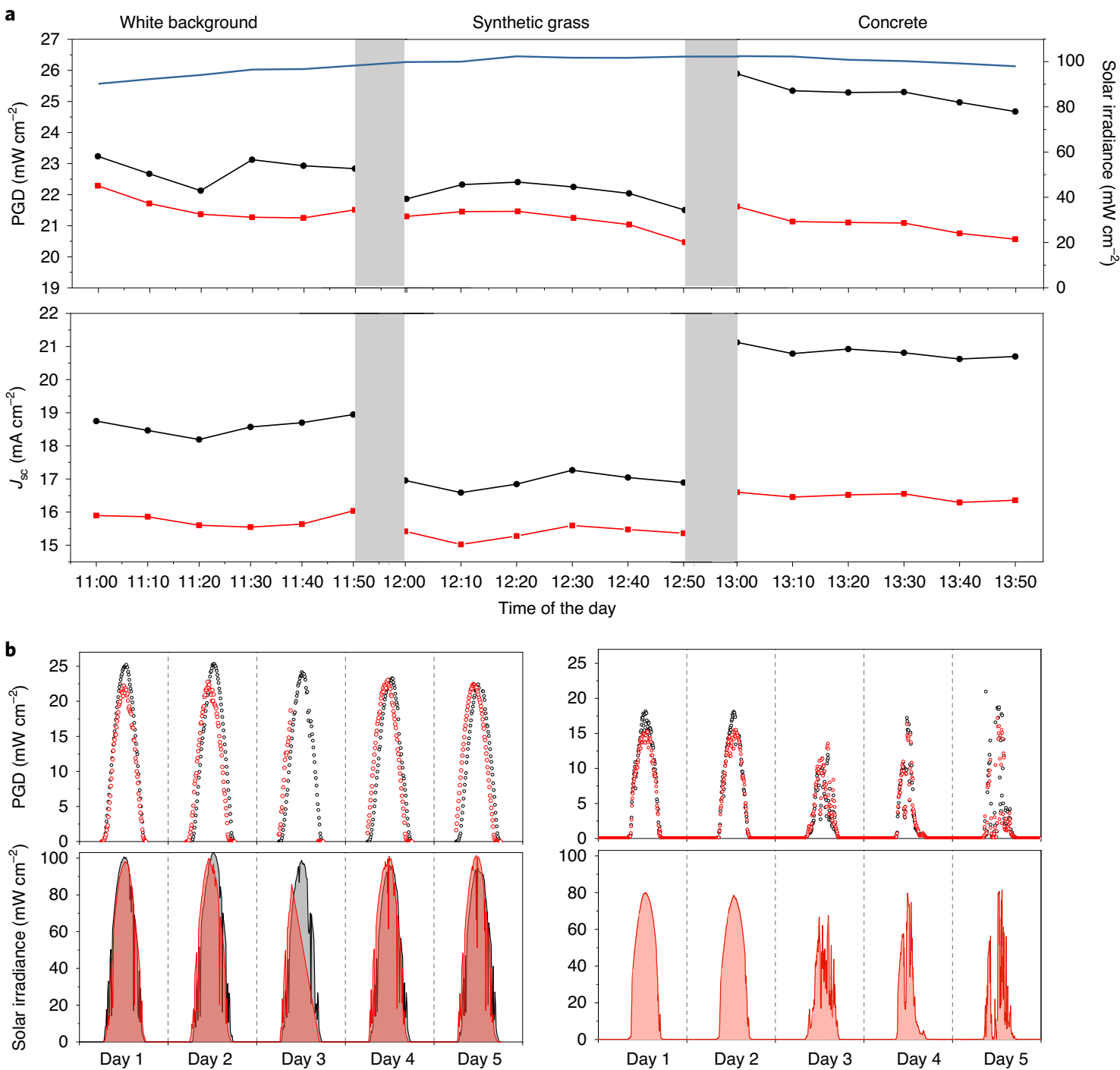

Fig. 3 Outdoor testing of bifacial tandems. a, Comparison of PGD (top) and $J_{\mathrm{sc}}$ (bottom) for bifacial (black) and monofacial (red) tandems with different albedo conditions - white background, synthetic grass and concrete. The perovskite bandgaps are 1.62 and $1.68 \mathrm{eV}$ for the bifacial and monofacial tandems, respectively. For each point, the current density and therefore the PGD are normalized with the respective to solar irradiance (blue line). The grey areas in the plot represent the operational time to change the set-up from one background to another. $\mathbf{b}$, Test field power conversion comparison for bifacial (black) and monofacial (red) tandems, measured over five days in two different locations: Jeddah (22.302494 $\left.{ }^{\circ} \mathrm{N}, 39.110737^{\circ} \mathrm{E}\right)$ and Karlsruhe $\left(49.094577^{\circ} \mathrm{N}, 8.429605^{\circ} \mathrm{E}\right)$. For the Jeddah experiment, the devices were placed in the test field at different times, and therefore we report the intensity of the solar irradiance (red for monofacial and black for bifacial) for each day. For the Karlsruhe experiment, the devices were placed in the test field at the same time, and therefore we report only a single solar irradiance (red). For each device, the perovskite bandgap was $1.62 \mathrm{eV}$.

and reflection losses translate into $J_{\mathrm{SC}}$ losses of $4.6 \mathrm{~mA} \mathrm{~cm}^{-2}$ and $3.1 \mathrm{~mA} \mathrm{~cm}^{-2}$, respectively. Infrared light transmission results in another $0.9 \mathrm{~mA} \mathrm{~cm}^{-2}$ loss in $J_{\mathrm{SC}}$. Photons that impinge on the bifacial tandem rear can only be absorbed by the c-Si bottom cell. Here, high-energy photons could be parasitically absorbed in the rear-contact stack of the SHJ cell. The two-side textured c-Si wafer aids in geometric light trapping, which reduces reflection losses in the $600-1,000 \mathrm{~nm}$ wavelength range. For wavelengths around $500 \mathrm{~nm}$, an important reflection loss apparently results in imperfect light incoupling in these prototypes with the given rear-contact layer stack. Future work can address this loss by optimizing the refractive index combination in the rear stack and thereby enhance the light incoupling from the rear side. Finally, we extended our simulation to the encapsulated device (Supplementary Fig. 12), which, as experiments already showed, suffers from slightly increased reflection losses.

\section{Outdoor performances}

To further test the potential of the technology, we compared the outdoor performance of monofacial and bifacial tandem devices under three different specific albedo conditions: concrete, synthetic grass and a white background. We installed the monofacial and bifacial devices in our outdoor test field on the King Abdullah University of Science and Technology (KAUST) campus and changed the ground material to simulate these different albedo conditions (see Supplementary Fig. 13 for more details, which include the reflectance data from these surfaces). In this way, the performance relies on albedo rather than rear irradiance.

For each condition, we recorded the $J-V$ characteristic with a time interval of ten minutes during a measurement time of one hour. To achieve maximum consistency, we carried out the experiments at peak sun hours, using a pyranometer and a calibrated c-Si solar cell to monitor the light intensity. Figure 3 a shows the PGD and the $J_{\mathrm{SC}}$ 

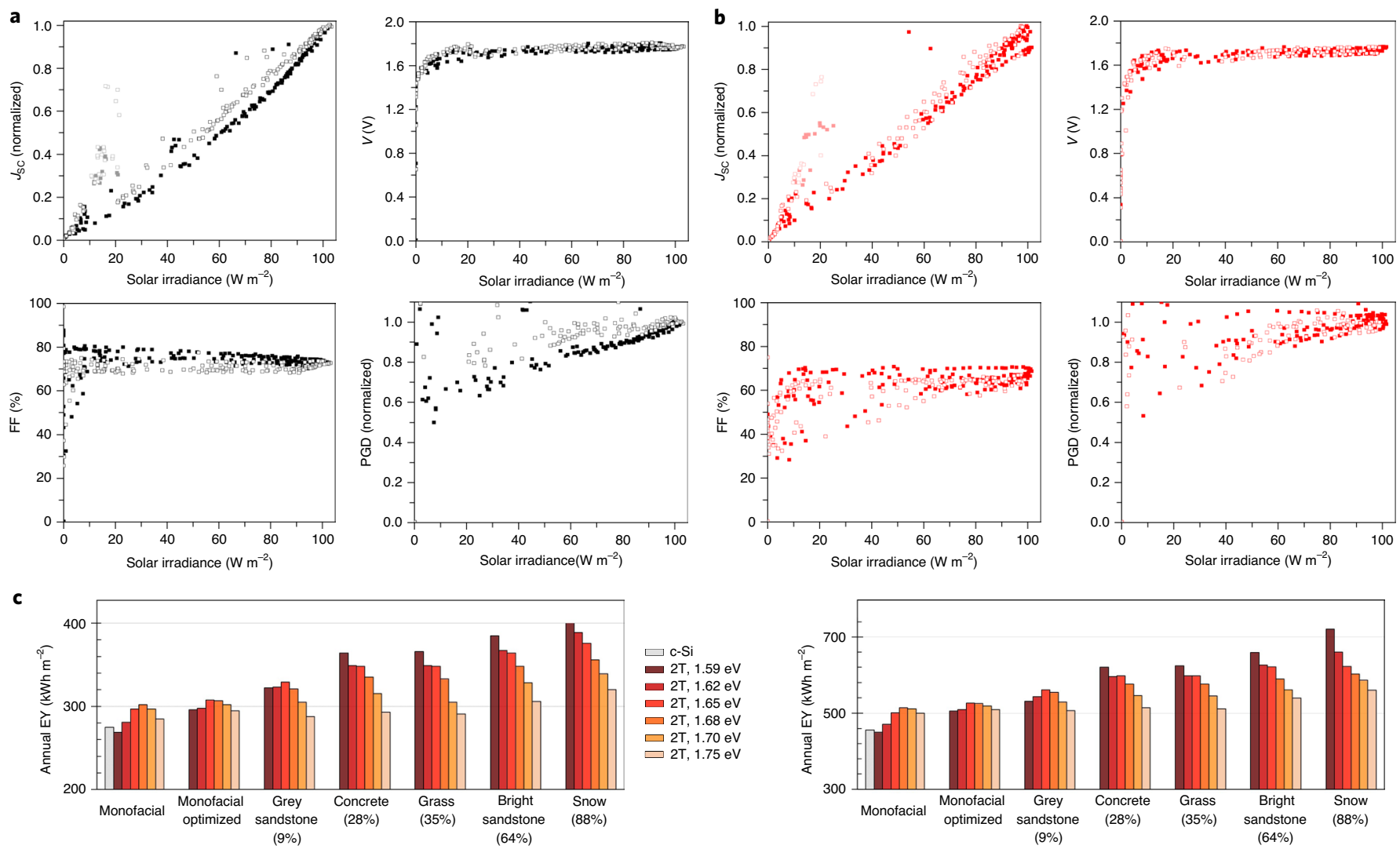

Fig. 4 | Analysis and energy yields of the test fields. a,b, $J_{\mathrm{SC} \text { tandem, }} V_{\mathrm{OC}}, \mathrm{FF}$ and PGD versus to the solar irradiance for the bifacial (a) and monofacial (b) tandems of Fig. 3b. For the $J_{S C}$ and PGD, the data are normalized to allow the comparison. The closed squares refer to data collected in the morning (06:00-12:00) and the open squares to data collected in the afternoon (12:00-18:00). c, Energy-yield (EY) calculations for monofacial and bifacial tandems with different perovskite bandgaps and under different albedo conditions, compared with that of a c-Si solar cell, at two locations in Seattle (left) and Phoenix (right).

of the bifacial (black) and monofacial (red) tandem devices. Both devices consist of the same layer stack apart from the rear electrode (opaque versus transparent electrode) and perovskite bandgaps. The bifacial tandem outperforms its monofacial counterpart for every albedo condition. The gain in performance was particularly striking when concrete was used as the ground-the bifacial tandem achieved a remarkable PGD of $25.9 \mathrm{~mW} \mathrm{~cm}^{-2}$. The increase in power output can be mainly attributed to the higher currents generated in the bifacial configuration. Overall, the average increase in bifacial power output was $20 \%$ for concrete, $6 \%$ for a white background and $4.3 \%$ for synthetic grass. We note that certain materials, such as snow, typically have an even larger albedo than concrete.

We extended the comparison between monofacial and bifacial tandems to test fields in two locations: Jeddah, which represents hot and sunny environments, and Karlsruhe, which represents a typical moderate climate. Figure $3 \mathrm{~b}$ shows the PGD of the bifacial tandems, from dawn (0:00) to dusk (18:00), measured at ten minute intervals over five days of investigation. To highlight the different irradiation conditions, we did not normalize the output power density to sun equivalents, but rather reported the Sun's intensity, obtained through a pyranometer and a calibrated c-Si reference cell. For the experiment, the cells were placed on test-field structures, with similar orientation and distance from the ground, that consisted of bright sand and concrete (Jeddah), and concrete (Karlsruhe). In both sites, the bifacial tandem performed significantly better than the monofacial one, particularly during midday when the light intensity was close to $100 \mathrm{~mW} \mathrm{~cm}^{-2}$ (Jeddah) or $80 \mathrm{~mW} \mathrm{~cm}^{-2}$ (Karlsruhe). Furthermore, the Karlsruhe data reveal that the enhancement in PGD is more pronounced on sunny days (days 1 and 2), which predominantly exhibit direct radiation compared with that on cloudy days with mostly diffuse irradiation (days 3-5).

In Fig. 4a,b, we report the analysis of performances of the bifacial and monofacial, respectively, tandems with respect to the solar irradiance for the five days of field data collected from the Jeddah location. As the data were collected under different solar irradiations, we normalized the $J_{\mathrm{SC} \text { tandem }}$ and the PGD for a direct comparison. For the $J_{\text {SC_tandem }}$, the trend of the monofacial tandem was linear. Conversely, for the bifacial tandem the current showed some hysteresis with the solar irradiance, with a sublinear behaviour during the morning (from 06:00 to 12:00) that became linear in the afternoon (from 12:00 to 18:00). The scattered data at low irradiance $\left(10-25 \mathrm{~mW} \mathrm{~cm}^{-2}\right)$ are an artefact induced by partial shading of the pyranometer during early mornings and late afternoons (Supplementary Fig. 14). To understand the behaviour of the current in the bifacial tandem, we measured the albedo of our test fields over five consecutive days (Supplementary Fig. 15). We found that, although the albedo is on an average constant during the week $(\sim 0.25)$, it fluctuates during the day, with lower values in the morning due to partial shading of the ground. This reflects the importance of controlling the albedo to maximize the performance of the bifacial tandem. The trend of the $V_{\mathrm{OC}}$ was similar for both devices, as the voltage reaches practically a constant value at solar irradiances of $15-20 \mathrm{~mW} \mathrm{~cm}^{-2}$ and higher. The FF shows a narrower distribution for the bifacial device, particularly at a low solar irradiance, without evident differences between morning and afternoon. Interestingly, for the bifacial tandem, the normalized PGD reflects 
the effect of the lower current during the morning, to improve in the afternoon. Overall, the normalized PGD distribution was similar for the two devices over the day.

Finally, we performed energy-yield simulations to assess the performance of bifacial tandems under realistic outdoor conditions (Fig. 4c). Two locations, Phoenix and Seattle, were chosen to represent two very different climatic conditions. Moreover, the annual energy yield was computed for different perovskite bandgaps and albedo conditions (see Methods and Supplementary Table 6 for more details). The highest monofacial energy yield was achieved with a perovskite bandgap of 1.68 and $1.65 \mathrm{eV}$ for both locations, using the identical layer stack of the bifacial architecture and an optimized perovskite thickness. Despite not featuring an ideal bandgap for monofacial tandems (which would be between 1.70 and $1.80 \mathrm{eV}$ ), this bandgap resulted in the most optimal current matching throughout the whole year for a $1,000 \mathrm{~nm}$ thick perovskite layer and thus achieved the highest energy yield. The lowest monofacial performance occurred for the smallest bandgap $(1.59 \mathrm{eV})$, due to significant current-mismatch losses. The scenario changed remarkably for the bifacial configuration. Even in the presence of ground with a reflectivity as low as that of dark grey concrete (average albedo reflectivity of $28 \%$ ), the optimum bandgap shifts to lower values: in Seattle, which represents a temperate climate, as well as in Phoenix, which represents a sunny, desert climate, it was $1.59 \mathrm{eV}$, due to the larger share of direct sunlight, which results in a stronger rear irradiance. Notably, bifacial energy-yield improvements of around $32 \%$ in Seattle and 37\% in Phoenix (relative to the best monofacial tandems with optimized layer thicknesses and a bandgap of $1.65 \mathrm{eV}$ ) were computed with a bandgap of $1.59 \mathrm{eV}$ for the perovskite and the most reflective ground. Materials with a high reflectivity could be used to enhance the albedo in locations with a large share of direct irradiation, to fully exploit the potential of bifacial perovskite/c-Si tandems with narrow perovskite bandgaps. Note that, to maintain generality, the energy-yield calculations provided in Fig. 4c do not consider installation-specific aspects, such as self-shading of the module or shading due to adjacent modules. For real-world applications, these aspects would lead to a site-specific reduction in the overall energy yield. However, as shown in Supplementary Figs. 16 and 17 , the key trends presented here are valid for representative installation scenarios that consider such shading losses.

\section{Conclusions}

We have experimentally shown how bifaciality can be used to enhance the performance of monolithic perovskite/c-Si tandems. The device configuration with a transparent back electrode relies on the albedo to enhance the current generation in the bottom cell and simultaneously enhance the current generation in the perovskite top cell, thanks to the application of a narrower perovskite bandgap. This matching is achieved for a $1.59-1.62 \mathrm{eV}$ bandgap perovskite, in which the bromide content is minimized compared with that in monofacial perovskite/c-Si tandems, thereby strongly reduces the stability issues related to halide segregation. We evaluated the bifacial tandem performance in test-field experiments and predicted the energy yield for bifacial and monofacial tandem configurations in different climates. In both cases, the bifacial tandem outperformed the monofacial configuration, which validates the promise of this technology. This work demonstrates the potential for a new class of efficient solar cells, which can close the gap with the $30 \mathrm{~mW} \mathrm{~cm}^{-2}$ PGD barrier, using a highly performant yet affordable technology. From here, further improvements in device performance and scaling-up of the technology are logical next steps to bring this technology closer to the photovoltaics market.

\section{Methods}

Device fabrication. SHJ bottom cells are fabricated on float-zone double side-textured four inch wafers (TOPSIL, $\mathrm{n}$-doped, resistivity $1-5 \Omega \mathrm{cm}^{-1}$ and thickness $250-280 \mu \mathrm{m})$. The wafers were processed with alkaline solution to obtain a random pyramid texture, after which they were cleaned in RCA1 and RCA2 solutions and dipped in hydrofluoric acid to remove the silicon oxide layer. The intrinsic $(5 \mathrm{~nm})$ and doped amorphous and nanocrystalline layers ( $\mathrm{p}$ and $\mathrm{n}, 12$ and $40 \mathrm{~nm}$, respectively) were deposited via plasma-enhanced chemical vapour deposition in an Octopus 2 cluster (Indeotec). The ITO rear contact $(100 \mathrm{~nm})$ and the recombination junction $(15 \mathrm{~nm})$ were sputtered in the physical vapour deposition part of the Octopus 2 cluster with a base pressure of $1 \times 10^{-5}$ torr, $13.56 \mathrm{MHz}$ radiofrequency source and $0.9 \mathrm{~W} \mathrm{~cm}^{-2}$ power density in an $\mathrm{Ar} / \mathrm{O}_{2}$ atmosphere $\left(0.8 \% \mathrm{O}_{2}\right.$ content) and the process pressure was $1 \times 10^{-3}$ torr (ITO target from Vital Thin Film materials-97\% $\mathrm{In}_{2} \mathrm{O}_{3} 3 \% \mathrm{SnO}_{2}$ ). After the physical vapour deposition, the bottom cells were annealed for $5 \mathrm{~min}$ at $200^{\circ} \mathrm{C}$. For the top cell, $\mathrm{NiO}_{x}(17 \mathrm{~nm}$, Plasmaterials) was sputtered (Angstrom EvoVac) at a base pressure of $<1 \times 10^{-6}$ torr in a pure Ar atmosphere with no intentional heating or cooling of the substrate, with a power density of $1.97 \mathrm{~W} \mathrm{~cm}^{-2}$ and a radiofrequency source of $13.56 \mathrm{MHz}$ (ref. ${ }^{32}$ ). Prior to the perovskite deposition, the $\mathrm{NiO}_{x}$ layer was passivated with 4 -bromobenzoic acid (Sigma Aldrich). The process was done by spin casting $2 \mathrm{mg} \mathrm{ml}^{-1} 4$-bromobenzoic acid in ethanol. After spin casting, the films were annealed at $90^{\circ} \mathrm{C}$ and, after cooling down, washed with ethanol several times. The triple cation perovskite solution $(1.68 \mathrm{M})$ was prepared in a $4: 1$ dimethylformamide:dimethyl sulfoxide solution (Sigma Aldrich) using $36.4 \mathrm{mg}$ of caesium iodide (Alfa Aesar), $44.8 \mathrm{mg}$ of methylammonium bromide (Greatcell), $389 \mathrm{mg}$ of fomamidinium iodide (FAI, Greatcell), lead bromide (Sigma Aldrich) and lead iodide (Alfa Aesar). The solution was stirred until complete dissolution of the precursors. The lead iodide and lead bromide amounts varied according to the desired bandgap. For the perovskite film formation, the perovskite precursors were spin coated on the bottom-cell substrate with a three-step process: initially at 600 r.p.m., then at 2,000 r.p.m. and finally at 7,000 r.p.m. During the acceleration between the second and third steps, anisole was dripped as a solvent quencher. Finally, the devices were annealed in nitrogen at $100^{\circ} \mathrm{C}$ for $15 \mathrm{~min}$. On top of the perovskite, lithium fluoride ( $1 \mathrm{~nm}$; Alfa Aesar) and $\mathrm{C}_{60}(20 \mathrm{~nm}$; NanoC) were thermally evaporated as the electron transport layer (Angstrom EvoVac). A layer of $20 \mathrm{~nm}$ of tin oxide $\left(\mathrm{SnO}_{x}\right.$, tetrakis(dimethylamino)tin and $\mathrm{H}_{2} \mathrm{O}$ as the precursors, with $\mathrm{N}_{2}$ as the gas carrier) was deposited via ALD (Picosun) and used as the protective buffer layer. As the top electrode, $110 \mathrm{~nm}$ of IZO were sputtered in an Angstrom EvoVac sputtering system (base pressure $<1 \times 10^{-6}$ torr) with a radiofrequency power of $42 \mathrm{~W}\left(90 \% \mathrm{In}_{2} \mathrm{O}_{3} / 10 \% \mathrm{ZnO}, 99.9 \%\right.$ Plasmaterials). To functionally contact the top and bottom transparent electrodes, we thermally evaporated (Angstrom EvoVac) $350 \mathrm{~nm}$ of silver contacts (base pressure $1 \times 10^{-6}$ torr) on the front and afterwards on the rear of the tandem using an aperture mask. Lastly, $95 \mathrm{~nm}$ of $\mathrm{MgF}_{2}$ as an antireflection film were thermally evaporated (Angstrom EvoVac) on top of the bifacial device.

Device characterization. To evaluate the performances of the tandems without rear irradiance, we used a calibrated Wavelabs Sinus 220 LED-based solar simulator with an AM1.5G irradiance spectrum as our light source and we coupled it with a Kiethley 2400 series SourceMeter to take the $J-V$ measurements. The data was recorded via a homemade MATLAB-based software. The solar cells were measured from -0.1 to $+1.9 \mathrm{~V}$ at $200 \mathrm{mV} \mathrm{s}^{-1}$ in both forward and reverse scan directions and the illuminated area, defined by a laser cut shadow mask, was $1.03 \mathrm{~cm}^{2}$. EQE measurements were performed using PV-Tools LOANA equipment. For the rear irradiance set-up we used an Abet Technologies Sun 3000 Class AAA and a Newport Oriel Sol3A Class AAA, both based on a xenon arc lamp. For the rear irradiance measurements, the stability test and the field-test investigation, we encapsulated the bifacial tandem with a vacuum laminator (Ecolam 5 Ecoprogetti) using glass and a $10 \mathrm{~mm}$ wide and $1 \mathrm{~mm}$ thick butyl rubber Solargain edge sealant with desiccant (Quanex, SET LP03).

Test-field experiment. For the field test, we used an $J-V$ tracer from EKO (model MP-160). The $J-V$ characteristics of multiple samples were probed successively using multiplexers MI-520, again from EKO. $J-V$ curves were acquired with a scan rate of $200 \mathrm{mV} \mathrm{s}^{-1}$, and we measured all the physical parameters in a time interval of $10 \mathrm{~min}$. The global horizontal irradiance on the plane of the devices was measured using a pyranometer MS-802 (EKO) mounted on the same structure as the devices. The solar cells were mounted on a structure with a tilt angle of $25^{\circ}$ and oriented south, located in KAUST's outdoor testing field on the KAUST campus, near the village of Thuwal $\left(22.302494^{\circ} \mathrm{N}, 39.110737^{\circ} \mathrm{E}\right)$. Furthermore, solar spectra were acquired using the spectrometers QE65PRO (visible spectral region) and NIRQuest512 (near-infrared spectral region) from Ocean Optics. The spectrometers were built into a temperature-controlled housing, and possess a wavelength resolution of $<2 \mathrm{~nm}$ across the entire visible to near-infrared spectrum. For the field test in Karlsruhe, we used a Keithley 2600 series SourceMeter to record the $J-V$ curves with a time interval of $3 \mathrm{~min}$. A homemade LabVIEW program was used to select successively the two solar cells using multiplexers and save the data. Then, through a MATLAB code, the maximum power point of each curve was extracted. The solar cells were mounted on a homemade metallic frame with a tilt angle of $45^{\circ}$ and oriented south. Calibrated c-Si solar cells mounted next to the bifacial cells were used to extract the suns, computed with the ratio between the short-circuit current in the test field for each data point and the short-circuit current under a solar simulator with an AM1.5G irradiance spectrum. 
Simulations and energy-yield modelling. The optical simulations and energy-yield modelling platform are accurately described elsewhere ${ }^{33}$. Here we provide a short description of the main features. The modelling platform combines four modules: (1) the optics module, (2) the irradiance module, (3) the electrics module and (4) the energy-yield core module. For the simulations in Fig. $2 \mathrm{c}, \mathrm{d}$ and Supplementary Fig. 6, the optics module alone was used. This module employs a combination of the transfer matrix method for thin, optically coherent layers, and series expansions of the Lambert-Beer law for optically thick layers, with multiple reflections at contiguous interfaces taken into account. Textured interfaces were handled using geometrical ray tracing, as suggested by Baker-Finch and McIntosh ${ }^{34}$ To model as closely as possible the fabricated devices, complex refractive indices of most of the layers were measured in-house at KAUST. The output of the module was stored in multidimensional matrices, namely, the reflectance matrix, the transmittance matrix and the absorptance matrix, for each layer in the stack. Each matrix was spectrally and angularly resolved for a discrete number of photon wavelengths and incoming angles. Data for normal incidence were used for the optical simulations in Fig. 2c,d and Supplementary Fig. 11. For the energy-yield simulations, the remaining three modules work together with the optics module. The irradiance module used typical meteorological year (TMY3) datasets from the National Renewable Energy Laboratory to compute angularly and spectrally resolved clear-sky irradiance data of hundreds of locations in the United States with a time resolution of $1 \mathrm{~h}$, using SMARTS (simple model of atmospheric radiative transfer of sunshine $)^{35,36}$. Then, a simple model was used to account for cloud coverage to obtain realistic direct and diffuse irradiance data ${ }^{37}$. The energy-yield core module combined the output of the irradiance and optics modules to compute the light-collected current $J_{\mathrm{ph}}$ in the perovskite and silicon subcells. The layer stack used in the energy-yield simulations models the experimental stack shown in Fig. 1. Only when needed, the absorber thicknesses were slightly adjusted to match the experimental current densities reported in Fig. 2b. A set of electrical parameters for the perovskite subcell were artificially created to maintain comparability between the tandem configurations with different bandgaps. In particular, for each bandgap $\left(E_{\mathrm{g}}\right)$, the ideality factor, dark saturation current density and parasitic resistances were adjusted so that the FF of the corresponding perovskite single junction was set to $80 \%$ and the $V_{\mathrm{OC}} / E_{\mathrm{g}}$ ratio to $76 \%$. For the energy-yield simulations, the cells were tilted with an angle of $27^{\circ}$ in Phoenix and $30^{\circ}$ in Seattle and oriented towards the south. In the bifacial configuration, the albedo contribution was computed using reflection data from the ECOSTRESS library ${ }^{38}$. Shading due to the module itself and the other rows of modules was not taken into consideration. Then, the electrics module was used to compute the maximum power point calling the circuit simulator LTspice. An equivalent circuit identical to that in Supplementary Fig. 2a was used for the simulations of the tandem perovskite/silicon cells. Finally, the energy-yield module was used to sum the contributions for each hour of the typical meteorological year and extract the annual energy yield. For the ground shading due to the module itself, for Supplementary Fig. 17 we used the method proposed by others ${ }^{39}$, in which the contributions of the albedo due to direct and diffuse irradiation are computed separately. To do this, we used geometrical view factors to estimate the reduction of the albedo ${ }^{40,41}$. For the direct irradiation, the presence of the module itself cast a shade on the ground. The corresponding view factor described the portion of the ground seen from the module which was in shadow and therefore did not contribute to albedo. For the reduction of the albedo that originates from diffuse irradiation, we computed for each point of the ground (described by two polar coordinates with their origin at the back of the module) a view factor that defined the solid angle from which the point was not receiving diffuse light due to the presence of the module. When the contributions of the albedo from each point of the ground were summed, the reductions computed for both cases were taken into consideration, which therefore reduced the light-collected current density (Supplementary Fig. 17).

Reporting summary. Further information on research design is available in the Nature Research Reporting Summary linked to this article.

\section{Data availability}

All data generated or analysed during this study are included in the published article and its Supplementary Information

Received: 19 March 2020; Accepted: 30 November 2020; 1. - -10

\section{References}

1. Best-Research Cell Efficiency Chart (NREL, 2020).

2. Aydin, E., De Bastiani, M. \& De Wolf, S. Defect and contact passivation for perovskite solar cells. Adv. Mater. 31, 1900428 (2019).

3. Al-Ashouri, A. et al. Conformal monolayer contacts with lossless interfaces for perovskite single junction and monolithic tandem solar cells. Energy Environ. Sci. 12, 3356-3369 (2019).

4. Leijtens, T., Bush, K. A., Prasanna, R. \& McGehee, M. D. Opportunities and challenges for tandem solar cells using metal halide perovskite semiconductors. Nat. Energy 3, 828-838 (2018).
5. Allen, T. G., Bullock, J., Yang, X., Javey, A. \& De Wolf, S. Passivating contacts for crystalline silicon solar cells. Nat. Energy 4, 914-928 (2019).

6. Aydin, E. et al. Zr-doped indium oxide (IZRO) transparent electrodes for perovskite-based tandem solar cells. Adv. Funct. Mater. 29, 1901741 (2019).

7. Dewi, H. A. et al. Highly efficient semitransparent perovskite solar cells for four terminal perovskite-silicon tandems. ACS Appl. Mater. interfaces 11, 34178-34187 (2019).

8. Chen, B. et al. Enhanced optical path and electron diffusion length enable high-efficiency perovskite tandems. Nat. Commun. 11, 1257 (2020).

9. Chen, B. et al. Blade-coated perovskites on textured silicon for $26 \%$-efficient monolithic perovskite/silicon tandem solar cells. Joule 4, 850-864 (2020).

10. Elshorbagy, M. H. et al. A monolithic nanostructured-perovskite/silicon tandem solar cell: feasibility of light management through geometry and materials selection. Sci. Rep. 10, 1-8 (2020).

11. Duong, T. et al. High efficiency perovskite-silicon tandem solar cells: effect of surface coating versus bulk incorporation of 2D perovskite. Adv. Energy Mater. 10, 1903553 (2010)

12. Hou, Y. et al. Efficient tandem solar cells with solution-processed perovskite on textured crystalline silicon. Science 367, 1135-1140 (2020).

13. Sahli, F. et al. Fully textured monolithic perovskite/silicon tandem solar cells with $25.2 \%$ power conversion efficiency. Nat. Mater. 17, 820-826 (2018).

14. Liang, T. S. et al. A review of crystalline silicon bifacial photovoltaic performance characterisation and simulation. Energy Environ. Sci. 12, 116-148 (2019)

15. Asadpour, R., Chavali, R. V., Ryyan Khan, M. \& Alam, M. A. Bifacial Si heterojunction-perovskite organic-inorganic tandem to produce highly efficient $\left(\eta_{T}^{*} \sim 33 \%\right)$ solar cell. Appl. Phys. Lett. 106, 243902 (2015).

16. Onno, A. et al. Predicted power output of silicon-based bifacial tandem photovoltaic systems. Joule 4, 580-596 (2020).

17. Dupré, O. et al. Design rules to fully benefit from bifaciality in two-terminal perovskite/silicon tandem solar cells. IEEE J. Photovolt. 10, 714-721 (2020).

18. Geerligs, L. J., Zhang, D., Janssen, G. J. M. \& Luxembourg, S. L. 4-Terminal and 2-Terminal Tandem Modules in Bifacial Operation: Model Analysis and Comparison http://resolver.tudelft.nl/uuid:a06611b9-78b2-46dd-8a04ca02cac50111 (2018)

19. Coletti, G. et al. Bifacial four-terminal perovskite/silicon tandem solar cells and modules. ACS Energy Lett. 5, 1676-1680 (2020).

20. Onno, A., Chen, C., Koswatta, P., Boccard, M. \& Holman, Z. C. Passivation, conductivity, and selectivity in solar cell contacts: concepts and simulations based on a unified partial-resistances framework. J. Appl. Phys. 126, 183103 (2019).

21. Lehr, J. et al. Energy yield modelling of perovskite/silicon two-terminal tandem PV modules with flat and textured interfaces. Sustain. Energy Fuels 2, 2754-2761 (2018)

22. Lehr, J. et al. Energy yield of bifacial textured perovskite/silicon tandem photovoltaic modules. Sol. Energy Mater. Sol. Cells 208, 110367 (2020).

23. Jacobs, D. A. et al. Light management: a key concept in high-efficiency perovskite/silicon tandem photovoltaics. J. Phys. Chem. Lett. 10, 3159-3170 (2019)

24. Gharibzadeh, S. et al. Record open-circuit voltage wide-bandgap perovskite solar cells utilizing 2D/3D perovskite heterostructure. Adv. Energy Mater. 9, 1803699 (2019)

25. Hoke, E. T. et al. Reversible photo-induced trap formation in mixed-halide hybrid perovskites for photovoltaics. Chem. Sci. 6, 613-617 (2015).

26. Boccard, M. \& Ballif, C. Influence of the subcell properties on the fill factor of two-terminal perovskite-silicon tandem solar cells. ACS Energy Lett. 5, 1077-1082 (2020)

27. Köhnen, E. et al. Highly efficient monolithic perovskite silicon tandem solar cells: analyzing the influence of current mismatch on device performance. Sustain. Energy Fuels 3, 1995-2005 (2019).

28. Bush, K. A. et al. 23.6\%-efficient monolithic perovskite/silicon tandem solar cells with improved stability. Nat. Energy 2, 1-7 (2017).

29. Holman, Z. C. et al. Parasitic absorption in the rear reflector of a silicon solar cell: simulation and measurement of the sub-bandgap reflectance for common dielectric/metal reflectors. Sol. Energy Mater. Sol. Cells 120, 426-430 (2014).

30. Liu, H. et al. A worldwide theoretical comparison of outdoor potential for various silicon-based tandem module architecture. Cell Rep. Phys. Sci. 1, 100037 (2020)

31. Guerrero-Lemus, R., Vega, R., Kim, T., Kimm, A. \& Shephard, L. Bifacial solar photovoltaics-a technology review. Renew. Sustain. Energy Rev. $\mathbf{6 0}$, 1533-1549 (2016).

32. Aydin E. et al. Room-temperature-sputtered nanocrystalline nickel oxide as hole transport layer for $\mathrm{p}-\mathrm{i}-\mathrm{n}$ perovskite solar cells. ACS Appl. Energy Mater. 1, 6227-6233 (2018)

33. Zhan, T., Xiong, J., Lee, Y.-H., Chen, R. \& Wu, S.-T. Fabrication of Pancharatnam-Berry phase optical elements with highly stable polarization holography. Opt. Express 27, 2632-2642 (2019)

34. Baker-Finch, S. C. \& McIntosh, K. R. Reflection of normally incident light from silicon solar cells with pyramidal texture. Prog. Photovolt. Res. Appl. 19, $406-416$ (2011) 
35. Wilcox, S. \& Marion, W. Users Manual for TMY3 Data Sets NREL/ TP-581-43156 (NREL, 2008).

36. Gueymard, C. A. Parameterized transmittance model for direct beam and circumsolar spectral irradiance. Sol. Energy 71, 325-346 (2001).

37. Schmager, R. et al. Methodology of energy yield modelling of perovskite-based multi-junction photovoltaics. Opt. Express 27, A507-A523 (2019).

38. Baldridge, A. M., Hook, S., Grove, C. \& Rivera, G. The ASTER spectral library version 2.0. Remote Sens. Environ. 113, 711-715 (2009).

39. Sun, X., Khan, M. R., Deline, C. \& Alam, M. A. Optimization and performance of bifacial solar modules: A global perspective. Appl. Energy 212, 1601-1610 (2018).

40. Hottel, H. C. \& Sarofim, A. F. Radiative Transfer (McGraw-Hill, 1967)

41. Appelbaum, J. View factors to grounds of photovoltaic collectors. J. Solar Energy Eng. 138, 064501 (2016).

\section{Acknowledgements}

This work was supported by the King Abdullah University of Science and Technology (KAUST) Office of Sponsored Research (OSR) under award no. OSR-2018-CPF-3669.02, KAUST OSR-CARF URF/1/ 3079-33-01, KAUST OSR-CRG RF/1/3383, KAUST OSR-CRG2018-3737 and IED OSR-2019-4208. This work was supported in part by the US Department of the Navy, Office of Naval Research (grant award no. N00014-20-1-

2572). The financial support of the German Federal Ministry for Economic Affairs and Energy (CAPITANO, funding code 03EE1038B) and the Initiating and Networking funding of the Helmholtz Association (HYIG to U.W.P. (funding code VH-NG1148), PEROSEED (funding code ZT-0024) and the Science and Technology of Nanostructures Research Program) is acknowledged. Furthermore, we are grateful for the help and support of A. Mertens and A. Rozalier from KIT in setting up the outdoor measurements in Karslruhe as well as M. Langenhorst, R. Schamger and J. Lehr for developing earlier versions of the energy-yield software. We acknowledge the support of ABET
Technologies and Newport. We thank TUV Rheinland Group, Germany, for providing solar spectra from TUV's outdoor test field on the KAUST campus, Thuwal, Saudi Arabia. We are grateful for the support of J. L. Mynar and the KAUST Corelab, and for the fruitful discussions with A. H. Balawi.

\section{Author contributions}

M.D.B. conceived the idea; M.D.B. and A.J.M. fabricated the devices; Y.H., B.C. and A.S.S. developed the perovskite bandgaps; E.A. developed the tandem top contact and layout; E.A. and F.H.I. developed the tandem hole transport layer; M.D.B., T.G.A. and E.V.K. developed the silicon bottom cell; F.G., U.W.P. and L.X. performed the optical modelling; J.L. performed the electrical modelling; M.F.S., F.G., J.T. and J.L. developed the field-test set-up; F.G. and U.W.P. performed the energy-yield calculations; M.F.S. supervised the field-test experiment; M.D.B., M.F.S., A.S.S., F.G. and U.W.P. wrote the manuscript; D.B., B.F., E.H.S. and S.D.W. supervised the project.

\section{Competing interests}

The authors declare no competing interests.

\section{Additional information}

Supplementary information is available for this paper at https://doi.org/10.1038/ s41560-020-00756-8.

Correspondence and requests for materials should be addressed to E.H.S. or S.D.W.

Peer review information Nature Energy thanks Gianluca Coletti and the other, anonymous, reviewer(s) for their contribution to the peer review of this work.

Reprints and permissions information is available at www.nature.com/reprints.

Publisher's note Springer Nature remains neutral with regard to jurisdictional claims in published maps and institutional affiliations.

(C) The Author(s), under exclusive licence to Springer Nature Limited 2020 


\section{Solar Cells Reporting Summary}

Nature Research wishes to improve the reproducibility of the work that we publish. This form is intended for publication with all accepted papers reporting the characterization of photovoltaic devices and provides structure for consistency and transparency in reporting. Some list items might not apply to an individual manuscript, but all fields must be completed for clarity.

For further information on Nature Research policies, including our data availability policy, see Authors \& Referees.

\section{- Experimental design}

\section{Please check: are the following details reported in the manuscript?}

1. Dimensions

Area of the tested solar cells

Method used to determine the device area

\section{Current-voltage characterization}

Current density-voltage (J-V) plots in both forward and backward direction

Voltage scan conditions

For instance: scan direction, speed, dwell times

Test environment

For instance: characterization temperature, in air or in glove box

Protocol for preconditioning of the device before its characterization

Stability of the J-V characteristic

Verified with time evolution of the maximum power point or with the photocurrent at maximum power point; see ref. 7 for details.

3. Hysteresis or any other unusual behaviour

Description of the unusual behaviour observed during the characterization

Related experimental data

\section{Efficiency}

External quantum efficiency (EQE) or incident photons to current efficiency (IPCE)

A comparison between the integrated response under the standard reference spectrum and the response measure under the simulator

For tandem solar cells, the bias illumination and bias voltage used for each subcell

\section{Calibration}

Light source and reference cell or sensor used for the characterization

Confirmation that the reference cell was calibrated and certified
XYes

$\square$ No

Xyes No

$\bigotimes$ Yes $\square$ No

$\varnothing$ Yes

$\square$ No

XYes

$\square$ No

$\square$ Yes

$\bigotimes$ No

ХYes

No Pmpp, Jmpp and Vmpp values were recorded during MPP trackin
certificate, Fraunhofer ISE CalLab also reported stabilized power.

QYes $\square$ No $\bigotimes$ Yes $\square$ No

Table S1, Figure S2, Table S2

ХYes

$\square$ No

$\triangle$ Yes $\square$ No

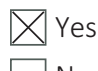

Reported in the methods section.

No

$\square$ Yes

$0.832 \mathrm{~cm} 2$ aperture area was used. All details are in the certificate (supplementary information) and main text.

It has been determined by a certification laboratory (CalLab, Fraunhofer ISE)

In the J-V graphs in the main text and in the table in the supplementary information

The voltage scan were done both Jsc to Voc and Voc to Jsc. The scan speed is given in the methods section. Dwell time was not applied during the measurements.

All details about the measurement conditions are added in the methods section.

Explain why this information is not reported/not relevant

Pmpp, Jmpp and Vmpp values were recorded during MPP tracking measurements. In

The observed hysteresis is negligible and mostly originated from the FF changes.

In the main text.

Fig. $2 b$

For in house measurements, AAA class LED based solar simulator was calibrated by using Farunhofer ISE CalLab certified c-Si cell.

The measurement of the device was carried out by the Farunhofer ISE CalLab. 
Calculation of spectral mismatch between the reference cell and the devices under test

6. Mask/aperture

Size of the mask/aperture used during testing

Variation of the measured short-circuit current density with the mask/aperture area

\section{Performance certification}

Identity of the independent certification laboratory that confirmed the photovoltaic performance

A copy of any certificate(s)

Provide in Supplementary Information

8. Statistics

Number of solar cells tested

Statistical analysis of the device performance

9. Long-term stability analysis

Type of analysis, bias conditions and environmental conditions

For instance: illumination type, temperature, atmosphere humidity, encapsulation method, preconditioning temperature
In methods and in the supplementary information Figure S2

No

$\square$ Yes

Our results are always reported with aperture. Farunhofer ISE CalLab measured the aperture area by themselves.

$\triangle$ Yes

CalLab, Fraunhofer ISE.

No

$\triangle$ Yes

Figure S2

No

$\bigotimes$ Yes

Fig. 1e and Fig. 1h

No

$\triangle$ Yes

Table S1

No

ХYes

No

We performed $85 \mathrm{C}$ accelerated stability in dark, mpp stability and field testing. Accelerated stability in dark and mpp were removed as per Reviewer request 